\title{
CLAVE DE IDENTIFICACIÓN DE LOS GÉNEROS MAS COMUNES DE AMMONOIDEA DE LA FORMACIÓN PUENTE INGA, MIEMBRO INFERIOR, TITONIANO SUPERIOR-BERRIASIANO INFERIOR DE LIMA
}

\author{
RESUMEN
}

Vera Alleman Haeghebaert ${ }^{1}$

Clave diferencial de ocho géneros de Lytoceratina y Ammonitina de la cuenca de Lima: Berriasella, Leptoceras, Limaites, Octagoniceras, Protacanthodiscus, Spiticeras, Substeueroceras y Thurmannites.

Palabras claves: Taxonomía, LYTOCERATINA, AMMONITINA, Jurásico-Cretáceo.

\section{SUMMARY}

We present a dichotomy key of Ammonites (Lytoceratina and Ammonitina) from Lima. Basin: Berriasella, ,Leptoceras, Limaites, Octagoniceras, Protacanthodiscus, Spiticeras, Substeueroceras and Thurmannites.

Key words: Taxonomy, Lytoceratina, Ammonitina, Jurasic-Cretaceous, Lima Basin

\section{INTRODUCCIÓN}

La presente clave taxonómica es un instrumento de trabajo que sirve como apoyo práctico para facilitar la identificación de ejemplares descritos e ilustrados por Carlos Lissón, 1907, y Rosalvina Rivera, 1951. La clave está destinada a ser utilizada por los estudiantes de la asignatura de Paleontología, pero también puede servir a un amplio público, a conservadores de museos, profesores de colegios y público en general interesado en identificar el nombre científico de los fósiles que se encuentran en el Norte de Lima. Esta clave no incluye los taxones que están en proceso de investigación asi como la identificación de las especies correspondientes a los géneros considerados. El objetivo del uso de la clave es con un fin didáctico y de difusión, ya que sirve de base en el dictado de nuestras prácticas de Paleobiología y del registro del material de las colecciones del Museo.

\section{ANTECEDENTES}

No se conocen propuestas de claves en ammonites peruanos con excepción de una clave de identificación para ammonites del Género Berriasella de la Formación Puente Inga, Miembro Inferior (Alleman, 2000). ria Natural "Vera Alleman Haeghebaert" registrados con el código VA010411 al VA991211. Estos ejemplares han sido recolectados mayormente en columna (inédito) por los alumnos de las asignaturas de Paleontología y de Paleobiología de la carrera de Biología durante sus prácticas de campo, entre los años 1990 y 2010, en los afloramientos de las localidades de Puente Inga y Cerro Candela. Estos afloramientos están atribuidos al Grupo Puente Piedra del Berriasiano Inferior, Jurásico Superior (Palacios y otros, 1992).

La determinación taxonómica de las muestras se realizó en base a las descripciones originales de los tipos (Lisson, 1907, Rivera, 1951) y a la consulta del material de "tipos" conservados en el Museo de Paleontología de la Universidad Nacional de Ingeniería (UNI) y del Departamento de Paleontología del Instituto Geológico, Minero y Metalúrgico (INGEMMET). No se ha realizado revisiones o actualizaciones taxonómicas desde Tapia (1988).

\section{RESULTADOS}

Phyllum MOLLUSCA *(según Moore 1957)

Clase CEPHALOPODA Leach. 1817

Orden AMMONOIDEA Zittel, 1884

\section{MATERIAL Y MÉTODOS}

Se examinaron un total de novecientos ejemplares depositados en las colecciones Alleman del Museo de Histo- 


\section{CLAVE DE IDENTIFICACIÓN}

1.

- Concha enrollada

- Concha desenrollada

2.

- Costillas fuertes y bien definidas sobre la totalidad del flanco

- Costillas tenues u obsoletas sobre una parte del flanco

3.

- Costillas lisas o parcialmente engrosadas

- Costillas con nudos bien pronunciados

4.

- Costillas con una hilera de nudos

- Costillas con dos o más hileras de nudos

5.

- Nudos periumbilicales redondos

- Nudos periféricos radiales poco pronunciados

6.

- Dos nudos por costilla

- Tres nudos por costilla

7.

- Costillas bifurcadas a la mitad de la altura del flanco

- Costillas bifurcadas a diferentes alturas del flanco

\section{DISCUSIÓN}

La construcción de la clave tiene como base los ocho géneros de ammonites taxonómicamente justificados y discutidos por Lisson (1907), Rivera (1951), Rivera y Alleman (1974), Tapia (1988) y Alleman (2000). Eventuales cambios de nomenclatura o actualizaciones que podrían haber sido introducidos en la literatura sin las debidas justificaciones y discusiones taxonómicas correspondientes sobre los tipos de Carlos Lisson y de Rosalvina Rivera, no han sido tomados en consideración en el presente estudio.

La presencia de otros géneros de ammonites, como por ejemplo Himalayites, Kilianella, entre otros, han sido descritos por los autores citados, pero ningún ejemplar ha podido ser localizado en las colecciones de las instituciones visitadas y tampoco contamos con ejemplares de estos géneros en nuestras colecciones. Además sus ilustraciones fotografiadas y publicadas carecen de la nitidez necesaria para poder incluirlos en el presente estudio.

Sin embargo, en nuestro material se presentan ejemplares de taxones no reportados hasta la fecha y que necesitan un estudio taxonómico profundizado. El
2

Leptoceras sp. (fig. 1)

3

Limaites sp. (fig.2)

7

4

5

6

Spiticeras sp. (fig. 3)

Thurmannites (fig. 4)

Protacanthodiscus sp. (fig.5)

Octagoniceras sp. (fig. 6)

Berriasella sp. (fig.7)

Substeueroceras sp. (fig.8)

estudiante usuario de la clave debe ser consciente que no todas las muestras del material colectado calzarán de forma apropiada con las características de la clave, es decir, las características de los fósiles hallados pueden coincidir o no con ésta. Sin embargo, en este caso, se recomienda que estas muestras puede ser clasificadas como CEPHALOPODA AMMONOIDEA sp.

\section{CONCLUSIÓN}

La clave permite identificar ocho de los géneros reportados en los afloramientos de la Formación Puente Piedra, Miembro Puente Inga, ubicados en las localidades de Cerro Candela y de Puente Inga: Berriasella, Leptoceras, Limaites, Octagoniceras, Protacanthodiscus, Spiticeras, Substeueroceras y Thurmannites.

Varios géneros reportados por los autores (Lissón, 1907; Rivera, 1951) no están en las colecciones científicas de Lima.

El material de las colecciónes de los afloramientos de Puente Inga y de Cerro Candela, guardado en el Museo de Historia Natural "Vera Alleman Haeghebaert" de la Universidad Ricardo Palma incluye varios taxones no 
reportados, hasta la fecha, en cuanto a su descripción e identificación.

\section{RECOMENDACIONES}

Es indispensable que se completen las colecciones científicas de Lima con un aporte de nuevo material de tipos taxonómicos. Es necesario publicar el catálogo ilustrado del registro de la colección de tipos taxonómicos por las instituciones depositarias.

Dentro del material guardado en nuestras colecciones se encuentran varios taxones que hasta la fecha no han sido objeto de reporte ni de estudios taxonómicos. Es recomendable realizar un catalogo ilustrado del registro de la colección y publicarlo.

Los afloramientos de la Formación Puente Inga están en peligro de desaparición debido a urbanización del sector. Es urgente poner las localidades de lo que subsiste de Cerro Candela (Fig. 9) y de Puente Inga (Fig. 10) bajo protección del Estado Peruano y del Ministerio de la Cultura. Ya se ha iniciado el trámite de protección de la localidad Puente Inga.

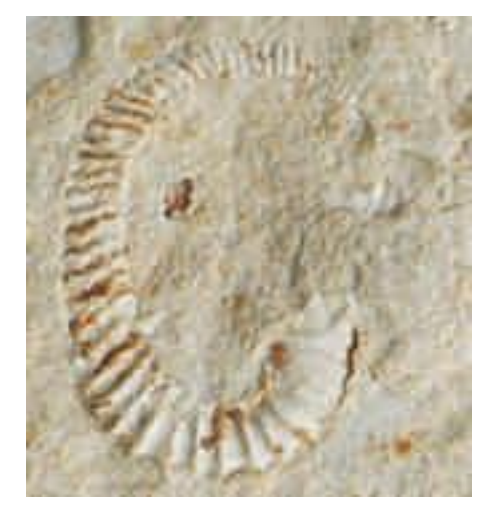

Fig. 1. Leptoceras sp.

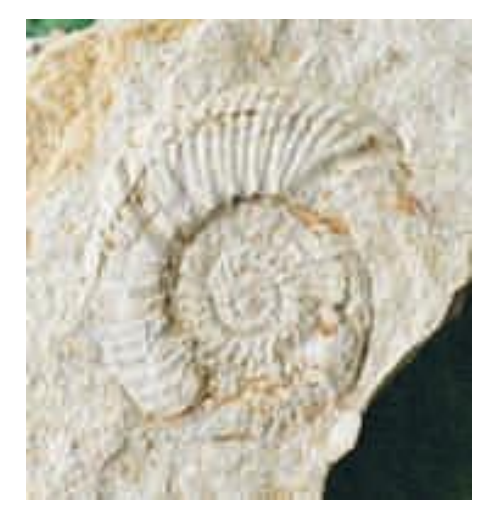

Fig. 3. Spiticeras sp.

\section{LITERATURA CITADA}

RIVERA, R. \& ALLEMAN, V. 1974. Fósiles “Tipos" conservados en el Perú. Boletín de la Sociedad Geológica del Perú. XLIV: 80-105.

ALLEMAN, V. 2000 Clave de Identificación para Ammonites del Género Berriasella de la formación Puente Piedra, Miembro Puente Inga, Lima. Biotempo 4: 50-52.

LISSON, C. 1907 Contribución a la Geología de Lima y sus Alrededores. Ed. GIL, pp.1-125, Lima

MOORE, R. 1975. Treatise on Invertebrate Paleontology. Part L, MOLLUSCA V. 4. University of Kansas, Kansas.

PALACIOS \& otros Geología de los Cuadrángulos de Lima, Lurín, Chancay y Chosica. Boletín Serie A: Carta Geológica Nacional No 43. INGEMMET: 1163.

TAPIA, P. 1988 Revisión bibliográfica de los Ammonoidea (Cephalopoda, Mollusca) del Cretáceo de Lima. Tesis Bachiller en Biología Universidad Ricardo Palma. Lima.

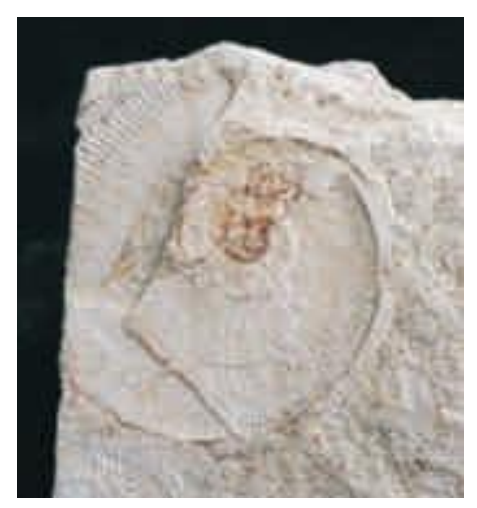

Fig. 2. Limaites sp.

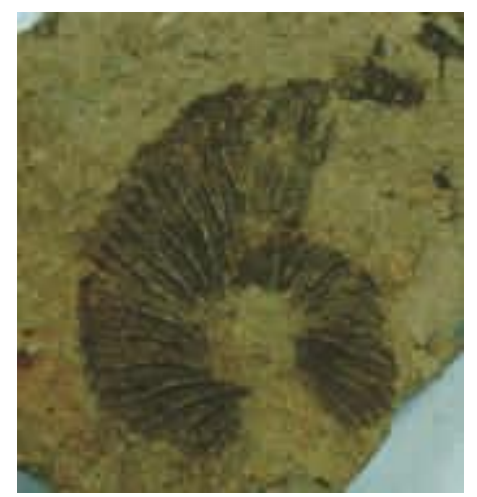

Fig. 4. "Thurmannites” douvillei en Lisson, 1907 (Lám. VII, Fig. 3) 


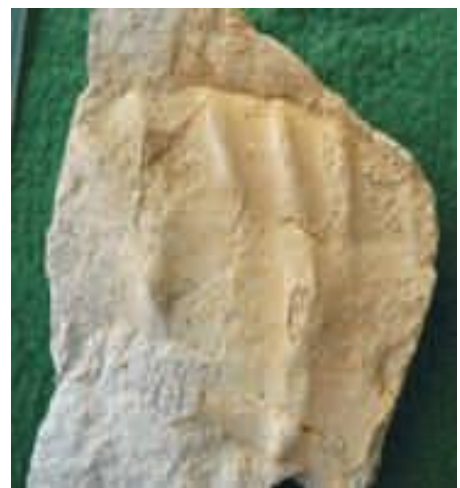

Fig. 5. Protacanthodiscus sp.

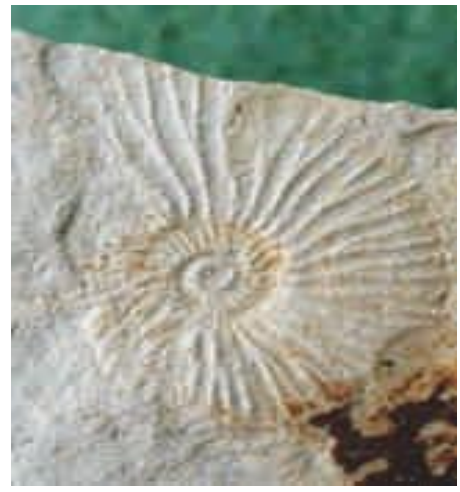

Fig. 7. Berriasella sp.

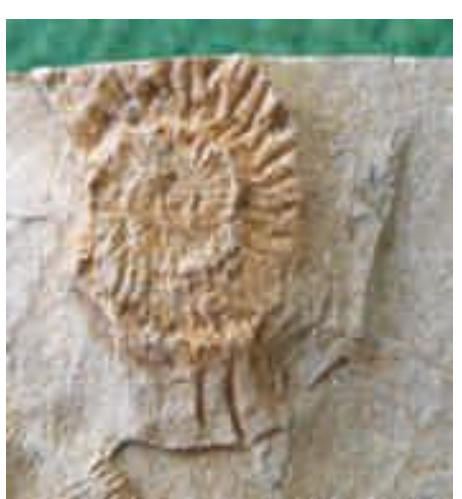

Fig. 6. Octagoniceras sp.

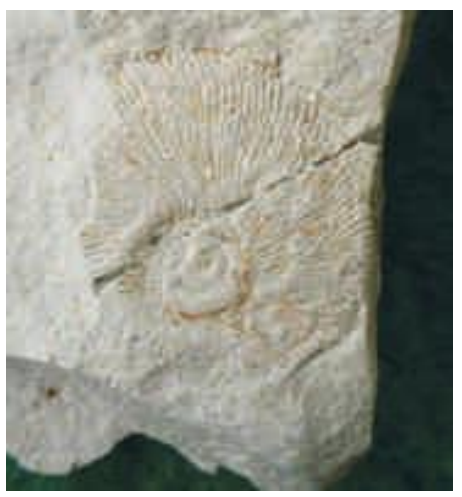

Fig. 8. Substeueroceras sp. 